\title{
DOSSIÊ
}

\section{História pública e cultura histórica na produção audiovisual contemporânea ${ }^{1}$}

\author{
Public history and historical culture in contemporary \\ audiovisual production
}

\author{
Josias José Freire Júnior \\ Doutor em História pela Universidade Federal de Goiás \\ Professor no Instituto Federal de Brasília \\ orcid.org/0000-0002-8524-7146 \\ freire.josias@gmail.com
}

\begin{abstract}
RESUMO: A racionalidade científica da ciência da história é garantida em sua produção, na historiografia, por meio de regras metodológicas que resultam no controle das etapas da pesquisa. Entretanto, a história não é capaz de controlar a circulação social desse conhecimento, para além de seu âmbito, embora a questão da apresentação da história também seja um de seus problemas. Sem dúvida uma das formas mais importantes de divulgação não estritamente historiográfica da história é o audiovisual, seja no cinema ou em outras mídias. Nesse contexto, apresenta-se nesse artigo reflexões com intuito de problematizar significados das narrativas audiovisuais veiculadas pela série televisiva "Guia Politicamente Incorreto" (2017), em discussões dos temas da história pública, da consciência e da cultura histórica. $\mathrm{O}$ artigo ora apresentado é resultado de pesquisa que objetivou discutir significados históricos da produção audiovisual, a partir da história pública e da didática da história, na série televisiva aqui analisada.
\end{abstract}

PALAVRAS-CHAVE: História pública. Cultura Histórica. Produção audiovisual.

\begin{abstract}
The scientific rationality of the history is guaranteed in its production, in historiography, through methodological rules of the research stages. However, history is not able to control the social circulation of this knowledge, beyond its scope, although the question of the presentation of history is also one of its problems. Undoubtedly one of the most important forms of dissemination that is not strictly historiographical in history is audiovisual, whether in the cinema or other media. In this context, reflections are presented in this article in order to problematize the meanings of audiovisual narratives broadcast by the television series "Guia Politicamente Incorreto" (2017), as a defendant in the themes of public history, conscience and historical culture. The article now presented is the result of a research that aimed to discuss historical meanings of audiovisual production, based on public history and the didactics of history, in the television series analyzed.
\end{abstract}

KEYWORDS: Public history. Historical Culture. Audiovisual production.

\footnotetext{
1 Pesquisa Financiada pelo Instituto Federal de Educação, Ciência e Tecnologia de Brasília (IFB).
} Desenvolvida com Bolsa de Iniciação Científica (IC-EM) CNPq. 
A particularidade científica da ciência da história, sua racionalidade específica, é garantida em sua produção, na historiografia, por meio de regras teórico-metodológicas que resultam no controle das etapas do processo de pesquisa. Essa compreensão está de acordo com o paradigma da ciência da história apresentado por Jörn Rüsen (2015, p. 72; 2001, p. 35) no que se refere à apresentação das inter-relações entre ideias, métodos e formas de apresentação da história científica, bem como do estreito vínculo dessas etapas com a vida prática. Desse modo, tais fatores do pensamento histórico são categorizado por Jörn Rüsen no âmbito do que ele chama de ciência especializada, para além da qual residem os elementos "vida prática", dimensão essa em que se originam as carências de orientação que motivam o conhecimento histórico em sentido amplo, e para a qual volta as funções de orientação do conhecimento histórico (RUSEN, 2001, p. 35), mas que não pode ser controlada pela dimensão cognitiva do conhecimento histórico.

A história científica, pois, não é capaz de controlar totalmente a circulação e a função social dos conhecimentos históricos, para além de sua esfera, embora a questão das múltiplas apresentações de histórias também seja um de seus problemas centrais, conforme pode-se discutir mais especificamente a partir dos temas da divulgação história, abordados por exemplo pelo campo da história pública, ou em termos bem mais gerais, e em nível categorial, pelas discussões acerca dos conceitos de consciência histórica de e cultura histórica, na didática da História e na teoria da história, respectivamente.

Ademais, contemporaneamente se reconhece que uma das formas mais importantes de divulgação não estritamente historiográfica do conhecimento histórico é a produção audiovisual, seja no cinema seja em outras mídias. Embora a divulgação científica escrita não tenha desaparecido, não se pode ignorar o predomínio da dimensão multimídia da revolução informacional dos dias atuais. Neste sentido, os significados da produção audiovisual para a ciência história e para o ensino de história ainda estão em aberto, especialmente com a diversificação e ampliação de gêneros e tipos daquela produção.

Nesse contexto, apresenta-se esse artigo, que tem por objetivo discutir alguns dos significados das narrativas audiovisuais veiculadas pela série "Guia Politicamente Incorreto", exibida pelo canal History em 2017, a partir de considerações sobre o campo da história pública, da consciência e da cultura histórica. Entende-se que alguns problemas relacionados à referida série e sua recepção se relacionam às questões da consciência e cultura históricas, podendo contribuir com a compreensão de significados do conhecimento histórico atualmente. As histórias veiculadas pela série tangenciam os conceitos da cultura e da consciência histórica na medida em que fornecem elementos para constituição de determinadas concepções de história, se aproximando do mesmo modo do campo da história pública, ao passo que sua produção é voltada para públicos mais amplos, como se verá.

Inicialmente serão apresentadas considerações sobre a relação entre produção audiovisual e conhecimento histórico, bem como sobre os conceitos de consciência histórica na didática da História, seguidas de discussões sobre o campo da história pública, do tema da cultura histórica e ainda de análises e discussões da série "Guia Politicamente Incorreto". Por fim, ao se problematizar a história veiculada pela série, 
especialmente as formas dessa veiculação - nas estratégias técnicas, estéticas e retóricas de reprodução de determinados conhecimentos históricos - se esclarecerá a importância de se considerar produtos midiáticos tais como o "Guia Politicamente Incorreto" para a produção e divulgação da história, seja em termos acadêmicos, escolares, ou para a divulgação para públicos mais amplos.

As muitas relações entre produção audiovisual e conhecimento histórico, os diferentes "usos", por assim dizer, que o conhecimento histórico faz do audiovisual em geral, promovem discussões que se disseminaram em diferentes contextos. Inicialmente, pelo reconhecimento desta produção, seja o cinema ou os diversos produtos da mídia, como fonte para produção do conhecimento histórico, passando pelos usos didáticos do audiovisual no ensino de história, e a produção de conhecimento histórico em âmbitos extra-escolares e extra-acadêmicos por aquelas mídias - na chamada história pública, conceituada e discutida logo em seguida. A consolidação daqueles usos foi fundamental e se deu paralelamente as reflexões sobre os seus significados para o conhecimento histórico.

As três dimensões das relações entre o audiovisual e o conhecimento histórico mencionadas, a saber, o audiovisual como fonte representação do passado, como recurso didático em sentido amplo, como meio de transmissão de determinado conhecimento, e enquanto referência para a produção do conhecimento histórico, emergiram a partir de registros teórico-metodológicos distintos que, embora façam referência à experiência fundamental da interpretação racional da condição humana no tempo, são específicos no que concerne aos tipos, elementos motivadores e funções daquela experiência. Tratase aqui, portanto, da perspectiva que reconhece o conhecimento histórico como experiência diversificada de interpretação racional da experiência humana (individual e coletiva) no tempo (RÜSEN, 2001; 2011), que pode ser identificado tanto na história acadêmica (teoria e historiografia), sua forma estritamente científica, quanto em outras formas racionais, como a história escolar (o ensino de História em geral) e história pública (divulgação científica de conhecimento histórico).

Nesse sentido, o audiovisual de temática histórica pode ser problematizado, no contexto de suas relações com o conhecimento histórico, também a partir de três abordagens, que coincidem em alguma medida com o mencionado estatuto do audiovisual para o conhecimento histórico: a compreensão do audiovisual "como documentos históricos", isto é, como testemunhos de determinado período histórico; "como discursos sobre a história", que constituem "críticas historiográficas" às "abordagens históricas"; e como produções que exercem "influência sobre os olhares do grande público a respeito da história" (SOUZA, 2012, p. 19) que, além de "construir significações históricas difusas e profundas" podem ser consideradas "como produtor[as] de novas abordagens, indutor[as] de outros olhares não pensados ou testados pela própria historiografia" (SOUZA, 2012, p. 21), colocando, portanto, novos problemas para a produção do conhecimento histórico-científico.

Acerca do reconhecimento da produção audiovisual como fonte para o conhecimento histórico em geral, entende-se que, apesar de a historiografia ser em sua origem predominantemente um tipo conhecimento vinculado à prática da escrita (ROSENSTONE, 2015, p. 14), há algum tempo se reconhece a importância da imagem 
Revista do Corpo Discente do Programa de Pós-Graduação em História da UnB

Em TEMPO DE HISTóRIAS | Brasília-DF | n. 37 | p. 561-575 | jul./dez. 2020.

ISSN 2316-1191

como fonte de conhecimento, em primeiro momento na história da arte (HAGEMEYER, 2012 , p. 40) e, pelo menos desde a primeira metade do século XX, como fonte para a produção da história em geral, isto é, como material a partir do qual pode-se se extrair determinadas informações sobre o passado com intuito de compreendê-lo historicamente. A compreensão de que o século XX foi o "século da imagem", em referência à "força que alcançou o mundo icônico no século passado, o seu crescente e progressivo protagonismo na vida cotidiana" (MONTÓN, 2009, p. 32), indica que já não se pode deixar de reconhecer a importância das "mídias visuais" na composição de nossa imagem - e também de nossos conhecimentos - sobre o passado (ROSENSTONE, 2015, p. 16-17).

Se as produções audiovisuais, naquelas duas primeiras abordagens mencionadas, indicam as "maneiras mais comuns de relacionar cinema e história" e "são resultado da transformação de um dos termos em objeto do outro: história como objeto do cinema, ou o cinema como objeto da história" (HAGEMEYER, 2012, p. 09), na terceira abordagem (do audiovisual como "indutor de outros olhares" sobre a história, cf. acima) se amplia o debate da produção audiovisual em direção à "dimensão transdisciplinar", voltada à compreensão da "conexão do pensamento histórico científico com a vida humana prática" (RÜSEN, 2015, p. 33), ou como a vida cotidiana demanda e consome o conhecimento histórico - e, por isso, o influencia significativamente. Essa dimensão é transdisciplinar na medida em que exige, para compreensão das relações entre saber histórico e vida, a mobilização de saberes diferentes ciências e disciplinas (história, sociologia, antropologia, ciências política, ciências da comunicação, etc.). Ademais, é necessário reconhecer que os "olhares" sobre a história contribui de modo determinante com uma maior ou menor ênfase na compreensão de sua cientificidade, de seus procedimentos racionais e de seu papel na vida contemporânea. Isto é, o audiovisual problematiza as motivações, a produção e as motivações que compõem o conhecimento histórico em sua passagem científica da vida prática pela ciência especializada e retorno aquela, no esquema do paradigma da história desenvolvido por Rüsen (RÜSEN 2015, p. 72; 2001, p. 35), e tomada aqui como referência.

Além da concepção do audiovisual como fonte para a produção de conhecimento histórico, já se discute, pois, como essa mídia pode possibilitar problematizações sobre a própria produção do conhecimento histórico, a partir, por exemplo, das questões da relação entre verdade e representação (HAGEMEYER, 2012, p. 114) e o problema da "montagem da narrativa" (HAGEMEYER, 2012, p. 45), ou ainda, no que tangencia de modo mais significativo o debate ora proposto, da relação entre a circulação social do saber histórico - entre cultura e consciência históricas - e sua reprodução e divulgação pela história pública na produção audiovisual. Isto é, para além de ferramenta de representação e construção da história e produto de contextos históricos específicos, a produção audiovisual pode contribuir para a promoção de reflexões teóricas e metodológicas, sobre a natureza e as particularidades da elaboração do conhecimento histórico, sua distribuição social e suas relações fundamentais com a vida.

Assim, o cinema e, em geral, o audiovisual, pode ser compreendido "não é apenas uma prática social, mas um gerador de práticas sociais", isto é, "além de ser um testemunho das formas de agir, pensar e sentir uma sociedade, é também um agente 
que suscita certas transformações, veicula representações ou propõe modelos" (LAGNY apud VALIM, 2012, p. 285). Naturalmente, além de compreendido, como mencionado, com produtor, reprodutor e transformador de práticas sociais, o audiovisual também deve ser reconhecido como constituidores de determinadas visões do passado, como produtor de determinados aspectos da cultura histórica.

No que se refere à abordagem das relações entre produção audiovisual para a televisão e o conhecimento histórico, ressalta-se inicialmente a função política dessa mídia, já em suas origens, por conta de suas características técnicas, como aponta Friedrich Kittler, principalmente devido ao seu caráter doméstico/nacional e seu alcance (KITTLER, 2016, p. 307), e consequentemente sua importância para compreensão da história. Se a televisão assume outro papel no contexto atual, diante das outras mídias digitais, certamente ela não abandona seu impacto político de formação de opinião e difusão privilegiada de informações, incluindo aqui versões da história.

Embora de relevância inquestionável no mundo contemporâneo, as relações entre a televisão e a produção do conhecimento histórico parecem interessar menos do que o papel do cinema na história (SORLIN, 2009, p. 41). Essa atenção menor à "instituição televisional", ainda para Pierre Sorlin (2009, p. 41), se relacionaria à natureza da narrativa televisiva (ora "abrupta", ora indefinida) e dificuldade de acesso aos arquivos televisuais - dificuldade também assinalada por Eugênio Bucci (2004, p. 191).

De todo modo, com "enorme implantação social", "pujança econômica e expansão em novas redes" (BUSTAMANTE apud GOBBI; KERBAUY, 2010, p. 220) a televisão contemporânea adquiriu grande relevância como produtora e reprodutora de conteúdos culturais, entre estes, conteúdos históricos - e incluídos nestes, concepções de história. Embora talvez não tenha despertado atenção suficiente, de acordo com Faye Sayer, os conteúdos históricos na televisão passaram nas últimas décadas por um processo de mistura de gêneros e formatos, consolidando atualmente a TV como uma dos principais e mais bem sucedidos meios de divulgação de histórias públicas (SAYER, 2015, p. 11201123), e talvez mesmo de protagonista na formação da ideia de história de um grande número de pessoas.

No que diz respeito aos produtos audiovisuais televisivos e suas relações com a história, indicam-se também as reflexões de Eugênio Bucci sobre o papel da televisão na memória coletiva. Para Bucci a "relação dos brasileiros com sua própria memória" é "mediada pela televisão" (BUCCI, 2004, p. 192) - destacando-se, assim, a importância da mídia televisiva, no início dos anos 2000, para o que aqui é compreendido como a parte da cultura histórica da sociedade. Esse inegável papel da televisão na formatação da compreensão da história que a sociedade brasileira tem, naturalmente se transformou com a emergência das "novas mídias", especialmente com a relativa descentralização da produção e reprodução do audiovisual - especialmente com a ampliação da oferta e consumo dos canais de TV "por assinatura", como é caso do Canal History. Trata-se, portanto, de uma ampliação e mesmo potencialização da capacidade da televisão de "reciclar o legado histórico, transformando-o" (BUCCI, 2004, p. 206), o que torna também bastante relevante o debate sobre não apenas quais histórias, mas qual concepção de história é construída pela televisão. A televisão se especializou em, além de reproduzir histórias, selecionar e adaptar essas histórias a partir das demandas 
das audiências, ressignificando de maneira relevante também o que se entende por história.

Concernente às relações entre a produção audiovisual e o ensino de História, pode-se inicialmente indicar o reconhecimento, por alguns de seus estudiosos, como relações marcada por muitas ambiguidades. Embora descoberto "tardiamente" pela escola (NAPOLITANO, 2009, p. 11), o "uso" do audiovisual e especificamente do cinema como proposta para o ensino de História acompanha a introdução dos meios de comunicação audiovisuais no contexto brasileiro, com a criação, por exemplo, do Instituto Nacional do Cinema Educativo (INCE) (HAGEMEYER, 2012, p. 121). Isto é, apesar de usados de maneira mais expressiva pelas escolas apenas mais recentemente, a percepção de que o uso do cinema no ensino de História é didaticamente interessante para esse ensino já está presente há bastante tempo. Outra das referidas ambiguidades relacionadas ao "uso" do audiovisual nas aulas de história aparece quando este é ao mesmo tempo visto como "novidade", que entusiasma, entretanto que sempre, ou pelo menos na maioria das vezes, permanece como "complementar" (SILVA, 2013, p. 153) à aula mais tradicional.

Pode-se adicionar às ambiguidades mencionadas o fato de que o audiovisual ainda ser associado a uma concepção de representação do conteúdo de história nas telas (o "uso" mais elementar do audiovisual pela história, como mencionado, cf. acima), por meio da exibição ou da produção (isto é, o audiovisual representando história). A gradual passagem da concepção do aluno como consumidor para a compreensão do aluno como produtor de saberes na escola e a associação dos aspectos produtivos da narrativa cinematográfica à produção do saber histórico talvez tenha contribuído para a reversão desse cenário de uso do audiovisual como mera representação, complementar, do passado. Esta nova percepção da escola como espaço de produção de saberes específicos reconhecer, dessa forma, o "saber escolar enquanto um saber com configuração cognitiva própria e original da cultura escolar" (MONTEIRO, 2003, p. 13), conferindo, pois, a estudantes e professores o status de não simples consumidores de saberes produzidos alhures, mas reconhecendo que alunos e "[...] professores dominam e produzem saberes, num contexto de autonomia relativa, numa construção que apresenta uma especificidade decorrente do fato de ser integrante da cultura escolar" (MONTEIRO, 2007, p. 13).

A compreensão da escola como local de produção de um saber histórico específico, resultado de mediações (MONTEIRO, 2007, p. 91) entre saberes acadêmicos, currículo escolar, demandas e contextos políticos, sociais e culturais, está presente também na reflexão da didática da História de vertente alemã, que se propõe analisar "todas as formas e funções do raciocínio e conhecimento histórico na vida cotidiana, prática" (RÜSEN, 2011, p. 32), incluindo aí, pois, como sua tarefa, a compreensão da circulação social do conhecimento histórico em âmbito extra-acadêmico, como por exemplo, na escola, e também em âmbito extra-escolar, na história que circula nos meios de comunicações, nas mídias. Aprender histórias vai além, consequentemente, de assimilar um conjunto de conhecimentos (acadêmico-historiográficos ou escolares), mas adquirir e desenvolver "a competência para atribuir significado ao tempo" (RÜSEN, 2011, p. 79), como "formação de uma consciência histórica" (BERGMANN, 1990, p. 30). 
Esse desenvolvimento da didática da História pode assim ser percebido no reconhecimento da "consciência histórica" como seu problema central. Para Klaus Bergmann, importante nome dessa vertente alemã da didática da História, essa tem como tarefas "investigar o que é apreendido no ensino da História [...] o que pode ser apreendido [...] e o que deveria ser apreendido [...]" (BERGMANN, 1990, p. 29). O conceito de consciência histórica se tornou, dessa forma, o problema central dessa tendência da didática da História. Segundo Rüsen a consciência história é "a suma das operações mentais com as quais os homens interpretam sua experiência da evolução temporal de seu mundo e de si mesmos, de forma tal que possam orientar, intencionalmente, sua vida prática no tempo" (RUSEN, 2001, p. 57). Dentre as várias questões que o conceito de consciência histórica oferece à reflexão teórico-historiográfica, destaca-se para esse conceito de que modo o pensar historicamente - que o conceito de consciência histórica tenta dar conta - é formado por diferentes processos, dentre os quais a assimilação de versões da história disponíveis no cotidiano.

Abre-se, pois, a possibilidade de se discutir, em uma conjugação de categorias e conceitos da teoria da história e da didática da História questões concernentes "circulação social do conhecimento histórico" (SADDI, 2012, p. 213) e a uma "teoria da aprendizagem histórica" e do "letramento em história" (CERRI, 2010, p. 270) no âmbito da aula de história, mas também para além dela. Desse modo, possibilita-se a reflexão tanto sobre os impactos sociais do ensino de História, quanto de que modo, não apenas por vias escolares, as concepções de história são produzidas e reproduzidas. Indica-se também referenciais para as discussões sobre como se aprende história - e sobre o significado de se aprender história, como tema fundamental da didática da História. Neste nível, é possível estabelecer a relação do debate aqui desenvolvido sobre outro campo de estudos, esse por sua vez dedicado às discussões da circulação de saberes histórico e das aprendizagens históricas em âmbito ainda mais aberto, dos meios de comunicação e das mídias; do saber histórico produzido e reproduzido para audiências ainda mais amplas: o campo da história pública.

A história pública é definida como o campo da reflexão histórica que se dedica à compreensão do saber histórico produzido para a chamada "divulgação histórica" (MAUAD; ALMEIDA; SANTHIAGO, 2016, p. 12). Surgida nos anos 1970 no contexto anglo-saxão (LUCCHESI; CARVALHO, 2016, p. 150), a história pública é, nesse sentido, produzida e destinada à ampliação de audiências não apenas acadêmicas (SANTHIAGO, 2016, p. 24) por meios específicos, isto é, da história que é produzida e reproduzida para além da (mas não ignorando) academia e da escola, em seus meios tradicionais (ALMEIDA; ROVAI, 2011). Por seu caráter intrinsecamente autorreflexivo, como uma de suas condições (RÜSEN, 2001, p. 13) a história incorpora para si os campos de sua produção que, em alguns outros campos do saber, se desenvolve genericamente na divulgação científica, no jornalismo e nas mídias em geral. Isto significa que, embora não coincida com a história acadêmica, a história pública é um problema da teoria da história - assim como o é a didática da História em sentido estrito.

A história pública considera novos atores, instâncias e meios na cadeia produtiva, por assim dizer, do conhecimento histórico acadêmico e escolar, e reconhece que a história produzida por e em tais, em ambientes públicos, abre importantes questões para 
as reflexões teórico-historiográficas contemporâneas. Comprometida com uma interpretação racional da experiência humana do tempo "em uma variedade de formas - para além dos foros acadêmicos tradicionais" (ZAHAVI, 2011, p. 53), a história pública dialoga significativamente com a história acadêmica e o ensino de História nas escolas, mas não se restringe a essas experiências, nem se estabelece a partir de relações de hierarquia com elas (FERREIRA, 2016, P. 133). A história pública se manifesta, por conseguinte, tradicionalmente nos museus, monumentos e lugares de memória e história, departamentos de governos e empresas encarregados da preservação de suas histórias, e nas últimas décadas, nos diferentes meios de comunicação, desde o centenário cinema, passando pelo rádio, a televisão e agora as "novas mídias".

A história pública cumpre, ademais, um papel crítico em relação ao processo de deslocamento "dos contextos de inserção social do conhecimento", bem como das noções de precedência e hierarquia da produção acadêmica em relação às demais formas racionais de produção de conhecimento histórico (KNAUSS, 2019, p. 48), a saber, o saber histórico escolar (CAIMI, 2015) e a própria história pública. A história pública também coloca reiteradamente questões acerca dimensões da relação humana racional com a experiência do tempo para a história escolar e a história acadêmica.

Reconhece-se, ademais, que história pública trabalha pelo menos em duas frentes: por um lado, em torno do esforço de "ampliar os públicos da História para além do saber especializado da produção acadêmica" e, por outro lado, com as tentativas de se "reconhecer as produções ligadas à História que produzem significado histórico, ainda que não operada exclusivamente por um historiador de ofício" (FERREIRA, 2016, p. 133). A história pública elabora e busca compreender, destarte, o significado de saberes históricos não acadêmicos, sejam os produzidos como história oficial, em história Estatal, comunitária e empresarial (SAYER, 2015) ou como história para o consumo (produtos culturais que tem a história como tema), para ficar nos exemplos mais comuns deste tipo de história. Naturalmente, os produtos audiovisuais de temática histórica, de caráter ficcional ou não, estão desde o início presentes nas produções do campo da história pública, especialmente por sua importância na divulgação científica (ALBIERI, 2011, p. 21).

Outra característica identificada na história pública é que, muitas vezes, ela se associa associada aos "negócios" (LIDDINGTON, 2011, p. 31-32), isto é, aos usos comerciais de determinado conhecimento histórico ou versão elaborada do passado - na forma de divulgação científica e, especialmente, conteúdo histórico para produções midiáticas. O principal objeto da reflexão da história pública é, portanto, a particularidade dessas histórias não acadêmicas e as suas muitas e complexas referências aos seus contextos sociais (RÜSEN, 2015, p. 72). A história pública se estabeleceu, dessa forma, como campo de discussão que se ocupa dos modos a partir dos quais conhecimentos históricos e versões sobre o passado ultrapassam a produção acadêmica em "histórias populares", tal como a veiculada na série "Guia Politicamente Incorreto".

As histórias públicas podem evidenciar, também para uma audiência mais ampla do que as pessoas que consomem historiografia ou frequentam aulas de história nas universidades e nas escolas, que as "batalhas pela memória ainda estão em curso no 
País" (QUADRAT, 2018, p. 220), ao passo que "ela é uma arena de disputas vigorosas, na qual adversários ideológicos lutam pelo legado, patrimônio e memória pública de acontecimentos ocorridos há muito ou há pouco tempo, e que ainda estão se desdobrando" (ZAHAVI, 2011, p. 53). Além da divulgação de histórias, a história pública pode caminhar, ainda de acordo com Samantha Quadrat, "juntamente com uma pedagogia da memória", como possibilidade de "construir coletivamente o conhecimento do passado através de novas subjetividades e diferentes narrativas sobre a experiência do horror" (QUADRAT, 2018, p. 220). Nesse ponto é relevante destacar que o "conhecimento do passado" que a história pública possibilita ampliar, deve incluir a compreensão do próprio papel do conhecimento histórico na sociedade contemporânea.

Nesse sentido, ressalta-se que, ao mesmo tempo que a história pública possibilita uma nova compreensão do passado a partir de outras linguagens e em direção à outros públicos, suas narrativas também estruturam uma determinada compreensão do que é a história e de como ela busca explicar o passado. Se a história pública inclui "em seu abrigo experiências de pesquisa e de narrativas há muito produzidas pelo público não acadêmico" (RODRIGUES, 2018, p. 280), este modo específico de se produzir e reproduzir a história também se torna, em alguma medida, referência, para o público mais amplo, do que se trata ao se produzir a história. Talvez em uma de suas dimensões ainda não tão discutidas, é necessário compreender a importante relação entre a história pública e a noção de cultura história com intuito evitar a naturalização da relação entre o conhecimento histórico científico e seu contexto (RÜSEN, 2015, p. 72), das origens e dos destinos conhecimento histórico na vida prática.

Os saberes históricos são fundamentais no processo de "orientação cultural' (RÜSEN, 2015, p. 143) humana diante das experiências do tempo. Além da história propriamente dita, a memória e a tradição constituem esse "acervo" de interpretações da experiência temporal, de modo a conferir o duplo sentido da orientação histórica, diante "das mudanças temporais de si e do mundo" (RÜSEN, 2001, p. 58). Por isso Jörn Rüsen considera a cultura histórica como o "campo da interpretação do mundo e de si mesmo, pelo ser humano, no qual devem efetivar-se as operações de constituição de sentido da experiência do tempo" (RÜSEN, 2007, p. 121) realizada pela consciência histórica, "enquanto lugar mental da cultura histórica" (RUSEN, 2015, p. 227).

Assim, entende-se que a cultura história se refere "às formas e dinâmicas da recordação coletiva (da memória histórica) e ao seu papel na vida em sociedade", fornecendo, pois, "uma espécie de substrato para a orientação no tempo, para o fortalecimento de identidades coletivas, para a coesão de grupos e a legitimação de domínios" (GONTIJO, 2019, p. 69). Ao passo que e "articula sistematicamente o aspecto cognitivo da elaboração da memória histórica, com o aspecto político e estético dessa mesma elaboração" (RÜSEN, 2007, p. 121), as discussões sobre a cultura histórica e suas dimensões contribuem de maneira significativa com a compreensão dos processos de produção de conhecimento histórico e de como ele se relaciona com a vida cotidiana, como demanda por orientação histórica e respostas a tais demandas.

No que se refere aos conhecimentos históricos, sabe-se que ao lado da história acadêmica, da historiografia, e da história escolar, a instrumentalização do conhecimento histórico ressignificados por uma cultura escolar específica, a história 
pública cumpre um papel fundamental na composição do sentido histórico da cultura histórica, enquanto "acervo' dos sentidos constituídos pela consciência histórica humana ao longo do tempo" (MARTINS, 2019, p. 55). Tal acervo reúne dados disponíveis em diferentes produtos culturais, desde os explicitamente marcados por uma cultura histórica - como museus, monumentos, livros de história - até aqueles que contribuem com a construção da experiência histórica de maneira mais sutil. A produção audiovisual que, representando ou não histórias, contribuem com a formatação de nossos interesses pela história, e da compreensão do papel social, da função prática da história para a vida, são importantes constituidores de cultura histórica contemporânea.

A produção audiovisual pode se relacionar, por conseguinte, com a produção do conhecimento histórico sob diferentes perspectivas, a partir de seus registros específicos nos âmbitos acadêmico, escolar e público. Dessa forma, a partir do entrecruzamento dos campos da história pública e das relações entre produção do conhecimento histórico e audiovisual, bem como dos conceitos de consciência e cultura histórica, pode-se discutir a série televisiva "Guia Politicamente Incorreto", de 2017, a partir do referencial teórico mencionado. Propõem-se compreender a produção e apresentação dessa série, tendo por base as concepções teóricas - referências, estratégias e natureza - e didáticas - no sentido de reprodução do conhecimento histórico para além de seu âmbito acadêmico, como na didática da História de vertente alemã (RÜSEN, 2011), e nos conceitos e a cultura e consciência histórias, engendradas pela série.

Produzida pela produtora de vídeo "Studio Fly" e veiculada pelo canal de televisão por assinatura History, a série "Guia Politicamente Incorreto" foi baseada no "Guia Politicamente Incorreto da História do Brasil", de Leandro Narloch (2009). Apesar da polêmica em torno de seu lançamento (OGASSAWARA; BORGES 2019), a análise aqui proposta se concentra nos elementos inerentes à série, especialmente aos conteúdos por ela veiculados, bem como as estratégias audiovisuais dessa veiculação.

Exibida a partir de novembro de 2017, a série teve sete de seus episódios analisados na pesquisa ora apresentada. Para tanto, se produziu instrumentos para extração, reunião e análise das informações da série. A partir destas informações, foi possível compreender aspectos do papel do "Guia Politicamente Incorreto" enquanto produto de divulgação histórica, portanto, em alguma medida, inscrita no âmbito da história pública, bem como promotora de determinada perspectiva histórica.

Os episódios do "Guia Politicamente Incorreto" têm cerca de 45 minutos duração e seus enredos são relativamente simples: partem de uma temática histórica em direção à suposta "desconstrução" do que é colocado como visões históricas tradicionais (por exemplo, a ideia genérica de que os indígenas eram "defensores" do meio ambiente, ep. 01), por meio de entrevistas com participantes especialistas, conhecedores da temática, a apresentação de fontes históricas que corroboram os relatos, bem como estratégias técnicas de convencimento - efeitos visuais, sonoros, animações, etc. Percebe-se, pois, que o "Guia Politicamente Incorreto" cria um efeito de verdade sobre a história relatada, pois as informações apresentadas são referendadas por depoimentos e fontes, embora seja fundamental considerar que esse procedimento acontece sempre de maneira imediata - não há mediação críticas das informações relatadas pelas testemunhas, ou extraídas das fontes -, resultando pois, em uma efeito ficcional de representação 
verdadeira da história, inscrevendo-se, pois de maneira muito específica no campo da história pública e da divulgação história, em um jogo que de certa forma faz referência à procedimentos metodológicos mais rigorosos, que dariam credibilidade aos temas apresentados.

A diversidade de temáticas abordadas nos episódios da série que foram analisados, passa pela questão indígena (ep. 01 e 04), ditadura militar no Brasil (ep. 02), racismo (ep. 03), cangaço (ep. 05), aviação (ep. 06), e história do Brasil (ep. 07). Embora dialoguem com temáticas importantes para os estudos históricos contemporâneos - como a questão indígena e o racismo - e recortes consagrados pela historiografia - como o história do Brasil - e para a História escolar, a assistência e análise da série indicou que, concernente à forma com que os temas dos episódios foram discutidos, a série reproduz seus temas principalmente enquanto curiosidades e trivialidades históricas, entre noções históricas que permeiam os discursos do senso comum, destacando aspectos que chamam mais atenção, ora por serem incomuns, (meras) opiniões polêmicas, mas também por serem episódios quase pitorescos das histórias narradas. Embora interpretações de eventos históricos por profissionais sejam veiculadas pela série, elas não parecem predominar na maneira com que o "Guia Politicamente Incorreto" apresenta os seus temas e, especialmente, constrói uma determinada concepção do que se trata, quando se apresenta a história. Ainda, destaca-se que temática "politicamente incorreta" do livro que deu origem a série (NARLOCH, 2009), revisionista e abertamente polemista, é diluída em um caráter muito mais informativo, de veiculação de opiniões fundamentadas apenas na autoridade dos entrevistas, e algo de entretenimento.

Em relação ao desenvolvimento da temática nos episódios analisados da série, como mencionado, são apresentados diferentes entrevistados que comentam os respectivos temas de cada episódio. Os participantes dos episódios são predominantemente identificados como escritores (nos episódios analisados aparecem entrevistados identificados como escritores dezenas vezes), seguidos jornalistas, e mais uma pluralidade de outros profissionais (historiadores, entre esses), sempre nomeados como tais. Neste sentido, pode-se se afirmar que a série, embora a diversidade dos entrevistados não signifique automaticamente a mesma diversidade de pontos de vista, se dedica a construir a perspectiva, sobretudo um efeito retórico-estético, de múltiplas opiniões sobre as temáticas, respondendo à demanda de determinada concepção de debates, polêmicas e controvérsias, que a própria série coloca como seu diferencial, sua singularidade. Há, pois, uma estratégia de construção de uma aparência de diversificação de opiniões sobre as temáticas apresentadas, conquanto a série "Guia Politicamente Incorreto" pode ser compreendida como muito mais um produto que reforça determinadas versões do senso comum, não cientificamente problematizadoras da história, embora se apresente, em seu marketing, enquanto tal - como produto comercial, para qual a propaganda cumpre às vezes o papel de construir uma aparência para o produto que o diferencia de si mesmo.

Concernente às estratégias audiovisuais empregadas nos episódios analisados da série, destaca-se a diversidade de recursos, bem como sua marcante qualidade técnica. Efeitos visuais e sonoros, de animação, computação gráfica, montagem de imagens históricas, presentes em todos os episódios analisados, indicam a inscrição da série no 
âmbito de produções audiovisuais comerciais produzidas profissionalmente, direcionadas ao grande público como produtos a serem consumidos. A série "Guia Politicamente Incorreto" pode ser considerada, dessa forma, um produto audiovisual de relevante qualidade técnica, e na qual essa qualidade faz parte indubitavelmente de suas estratégias de divulgação e colocação no mercado como produto que visa ser bemsucedido comercialmente. Cumpre-se, desse modo, reconhecer que não pode ser ignorado ao sentido da narrativa audiovisual desenvolvido pela série, as funções sociais que os saberes históricos por ela reconstruídos em linguagem audiovisual, não podem ser desvinculados de seus elementos técnicos como estratégia de convencimento e cumprimento de seus objetivos enquanto produto comercial.

Nessa mesma direção, ao se considerar a série de seu ponto de vista temático, narrativo, suas escolhas técnicas e estratégias audiovisuais, entende-se que nessa diversificação de fontes, de conteúdos e recursos, tal série se apresenta como produto cultural-midiático que se inscreve em locus entre entretenimento e divulgação de um tipo conhecimento, com funções sociais diversificadas, mas voltada a um nicho específico de consumidores - o espectador típico do canal de televisão que a divulgou no Brasil. De maneira imediata, a série comunica comercialmente, por assim dizer, histórias produzidas a partir do que poderia ser considerado procedimentos metodológicosdisciplinares, naturalmente oriundos de noções do entendimento comum do que seja a busca por uma versão verdadeira do passado, como o suposto confronto de versões ou a indicação de fontes, inseridos em um contexto de entretenimento comercial, não problematizador e não reflexivo, com recursos e estratégias características desse universo.

Como re-produtora de saberes científicos em linguagem audiovisual, a série "Guia Politicamente Incorreto" deve ser compreendida como produto midiático típico, no qual os limites entre a comunicação de conhecimentos, produção informações e entretenimento são cada vez mais tênues. Consequentemente, as análises desenvolvidas acerca do "Guia Politicamente Incorreto", em seus desdobramentos e resultados, passam por considerações em diferentes níveis, sobre as relações entre o conhecimento histórico e a produção audiovisual, o papel da história pública no mundo contemporâneo e o significado da série aqui analisada como produto cultural de sua época.

No que se refere à relação entre produção do conhecimento histórico e produção audiovisual, pode-se encaminhar que tal relação está mais estreita do que nunca, e que o debate escolar e acadêmico sobre os "usos" de produtos audiovisuais como fonte e instrumento para a produção e reprodução de conhecimento tende a acompanhar a diversificação desses produtos, que ao se adequarem às demandas do mercado cultural contemporâneo, deverão apresentar renovadas questões aos pesquisadores da área de história.

Já acerca dos desenvolvimentos do campo da história pública, é necessário reconhecer que a divulgação histórica extra-escola e extra-academia está consolidada em produtos culturais e responde por um mercado em expansão, que não tem fronteiras claras entre divulgação científica e entretenimento. Indica-se também a qualidade de alguns destes produtos, como a série ora analisada, destacando a importância da 
profissionalização dessas produções, especialmente as que objetivam disputar o mercado audiovisual em seus diferentes âmbitos.

Por fim, ressalta-se o papel da relação entre o conhecimento histórico e as formas mais contemporâneas linguagens midiáticas, dentro de gêneros diversificados e que necessitam ter sua relevância para a formação histórica dos seus consumidores reconhecida. Reconhece-se assim que, além da tradicional função cumprida pelas histórias acadêmica e escolar, é necessário mais do que nunca reconhecer o espaço e tentar compreender o papel, para as ideias de história que circulam na sociedade, dos meios de comunicação e das novas mídias em sua constituição.

\section{Referências}

ALBIERI, Sara. Apresentação. In: ALMEIDA, Juniele; ROVAI, Marta (org.). Introdução à História Pública. São Paulo: Letra e Voz, 2011.

BERGMANN, Klaus. A História na Reflexão Didática. Revista Brasileira de História. São Paulo. V. 09, N. 19. 1989/1990. Disponível em < http://twixar.me/frS1 > Consultado em 26/08/2019.

BUCCI, Eugênio. A História Na Era De Sua Reprodutibilidade Técnica. In: BUCCI; KEHL. Videologias: Ensaios sobre televisão. São Paulo: Boitempo, 2004.

CAIMI, Flávia. Investigando os caminhos recentes da história escolar: tendências e perspectivas no ensino e pesquisa. ROCHA, Helenice; MAGALHÃES, Marcelo; GONTIJO, Rebeca (org.). O Ensino de História em Questão. Rio de Janeiro: FGV Editora, 2015.

CERRI, L. F. Didática da História: uma leitura teórica sobre a História na prática. Revista de História Regional 15(2): 264-278, Inverno, 2010. Disponível em < http://twixar.me/NrS1 > Consultado em 26/08/2019.

FERREIRA, Rodrigo. O cinema na história pública: balanço do cenário brasileiro (20112015). In: GOBBI, MC; KERBAUY, M (orgs). Televisão Digital: informação e conhecimento [online]. São Paulo: Editora UNESP; São Paulo: Cultura acadêmica, 2010.

GONTIJO, Rebeca. Cultura Histórica. FERREIRA, Marieta; OLIVEIRA, Maria (coord.). Dicionário de ensino de história. Rio de Janeiro: FGV Editora, 2019.

MARTINS, Estevão. Consciência Histórica. Dicionário De Ensino De História. Rio De Janeiro: Fgv Editora, 2019.

FERRO, Marc. Cinema e História. Trad. Flávia Nascimento. Rio de Janeiro: Editora Paz e Terra, 1992.

HAGEMEYER, Rafael. História \& Audiovisual. Belo Horizonte: Autêntica, 2012.

KITTLER, Friedrich. Midias ópticas: Curso em Berlim, 1999. Trad. Markus Hediger. Rio de Janeiro: Contraponto, 2016. 
KNAUSS, Paulo. Conhecimento Histórico Acadêmico. FERREIRA, Marieta; OLIVEIRA, Maria (coord.). Dicionário de ensino de história. Rio de Janeiro: FGV Editora, 2019.

LUCCHESI, Anita; CARVALHO, Bruno. História Digital. Reflexões, experiências e perspectivas. In: MAUAD, Ana Maria; ALMEIDA, Juniele; SANTHIAGO, Ricardo (org). História pública no Brasil: Sentidos e Itinerários. São Paulo: Letra e Voz, 2016.

MAUAD, Ana Maria; ALMEIDA, Juniele; SANTHIAGO, Ricardo (org). História pública no Brasil: Sentidos e Itinerários. São Paulo: Letra e Voz, 2016.

MONTEIRO, Ana Maria. Professores de História: Entre Saberes e Práticas. Rio de Janeiro: Mauad X, 2007.

MONTEIRO, Ana Maria. A História Ensinada: Algumas Configurações do Saber Escolar. História \& Ensino. V. 9, p. 37-62, out. 2003. Disponível em < http://twixar.me/GqS1 > Consultado em 26/08/2019.

MONTÓN, Angel Luis Hueso. O Homem E O Mundo Midiático No Princípio De Um Novo Século. In: NÓVOA, Jorge; FRESSATO, Soleni; FEIGELSON, Kristian (org.) Cinematógrafo: Um Olhar Sobre A História. Salvador: EDUFBA; São Paulo: Ed. da UNESP, 2009.

NARLOCH, Leandro. Guia politicamente incorreto da história do Brasil. Rio de Janeiro: Leya, 2009

NAPOLITANO, Marcos. Como Usar o Cinema na Sala de Aula. 4 ed. São Paulo: Contexto, 2009.

OGASSAWARA, Juliana Sayuri; BORGES, Viviane Trindade. O historiador e a mídia: diálogos e disputas na arena da história pública. Revista Brasileira de História. São Paulo, v. 39, no 80, 2019. Disponível em < http://twixar.me/J8y1 >. Consultado em 19/08/2019.

QUADRAT, Samantha Viz. É possível uma história pública dos temas sensíveis no Brasil? In: MAUAD, Ana Maria; SANTHIAGO, Ricardo; BORGES, Viviane (org.). Que História Pública Queremos? São Paulo: Letra e Voz, 2018.

ROSENSTONE, Robert. A história nos filmes, os filmes na história. Trad. Marcello Lino. 2. Ed. Rio de Janeiro: Paz e Terra, 2015.

RÜSEN, Jorn. Teoria da História: Uma Teoria da História Como Ciência. Trad. Estevão Martins. Curitiba: Editora UFPR, 2015.

RÜSEN, J. Didática da História: passado, presente e perspectivas a partir do caso alemão. In: SCHMIDT, M. A.; BARCA, I.; MARTINS, E. R (org). Jörn Rüsen E O Ensino de História. Curitiba: Ed. UFPR, 2011.

RÜSEN, Jörn. História Viva: Teoria da História: Formas e Funções do Conhecimento Histórico. Trad. Estevão de Rezende Martins. Brasília: Editora Universidade de Brasília, 2007.

RÜSEN, Jörn. Razão Histórica: teoria da história. Fundamentos da ciência histórica. Trad. Estevão Martins. Brasília: Editora da Universidade de Brasília, 2001. 
SADDI, Rafael. O Parafuso da Didática da História. Acta Scientiarum. Education. Maringá, v.34, n. 2, p. 211-220, July-Dec., 2012. Disponível em < http://twixar.me/PrS1 $>$ Consultado em 26/08/2019.

SAYER, Faye. Public History: A Pratical Guide. London, New York, Bloomsbury Academic, 2015.

SORLIN, Pierre. Televisão: Outra Inteligência do Passado. In: NÓVOA, Jorge; FRESSATO, Soleni; FEIGELSON, Kristian (org.) Cinematógrafo: Um Olhar Sobre A História. Salvador: EDUFBA; São Paulo: Ed. da UNESP, 2009.

SOUZA, E. C. Cinema e didática da história: um diálogo com o conceito de cultura histórica de Jörn Rüsen. Doi: 10.5216/hr.v17i1.21682. História Revista, 17(1). 2012. Disponível em: https://doi.org/10.5216/hr.v17i1.21682. Consultado em 27 de abr de 2020.

VALIM, Alexandre. História e Cinema. In: CARDOSO, Ciro Flamarion; VAINFAS, Ronaldo (org.). Novos Domínios da História. Rio de Janeiro: Ed. Elsevier, 2012.

ZAHAVI, Gerald. Ensinando História Pública. In: ALMEIDA, Juniele; ROVAI, Marta (org.). Introdução à História Pública. São Paulo: Letra e Voz, 2011. 